\title{
Five-year overall survival following chemoradiation therapy for locally advanced cervical carcinoma in women living with and without HIV infection in Botswana
}

Emily MacDuffie ${ }^{1}$, Memory Bvochora-Nsingo ${ }^{2}$, Sebathu Chiyapo ${ }^{3}$, Dawn Balang ${ }^{2}$, Allison Chambers ${ }^{4}$, Jessica M. George ${ }^{5}$, Shawna Tuli, Lilie L. Lin ${ }^{6}$, Nicola M. Zetola ${ }^{1,7}$, Doreen Ramogola-Masire ${ }^{8,9}$ and Surbhi Grover ${ }^{1,3,7,8^{*}}$ (i)

\begin{abstract}
Purpose: To compare updated prospective 5-year survival outcomes of cervical cancer patients living with and without human immunodeficiency virus (HIV) infection who initiated curative chemoradiation therapy (CRT) in a resource-limited setting.
\end{abstract}

Methods \& Materials: Women in Botswana with locally advanced cervical cancer were enrolled in a prospective, observational, cohort study from July 2013 through January 2015. Survival outcomes were analyzed after 5 years of follow-up. Results: This cohort included 143 women initiating curative CRT. Sixty-seven percent $(n=96)$ of cohort were women living with HIV (WLWH), all of whom were receiving antiretroviral therapy (ART) at the time of treatment initiation and boasted a median CD4 count of 481 cells/ $\mu \mathrm{L}$ (IQR, 351-579 $\mu \mathrm{L}$ ). The 5-year overall survival (OS) rates were $56.8 \%$ (95\% Cl, 40.0-70.5\%) for patients without HIV infection and $55.1 \%$ (95\% Cl, 44.2-64.7\%) for WLWH ( $p=0.732)$. Factors associated with superior 5-year OS on multivariate analyses included baseline hemoglobin $>10 \mathrm{~g} / \mathrm{dL}$ (hazard ratio (HR) 0.90, 95\% Cl, 0.83-0.98, $p=0.015$ ), lower stage at diagnosis (stage I and II vs. III and IV) (HR 1.39, 95\% Cl 1.09-1.76, $p=0.007)$, and higher EQD2 (HR 0.98, 95\% Cl $0.97-0.99, p=0.001)$.

Conclusions: Five-year OS was not impacted by HIV status in this population of WLWH with well-managed infection who initiated curative treatment for cervical cancer in Botswana. Regardless of HIV status, hemoglobin levels and stage at diagnosis were associated with survival. These findings suggest that treatment for cervical cancer in WLWH with wellcontrolled infection need not be altered solely due to HIV status.

Keywords: Cervical cancer, Chemoradiation, HIV, Botswana, Sub-Saharan Africa, Low resource setting, Survival outcomes

\footnotetext{
* Correspondence: Surbhi.grover@uphs.upenn.edu

'Department of Radiation Oncology, Perelman School of Medicine, University

of Pennsylvania, Philadelphia, USA

${ }^{3}$ Princess Marina Hospital, Gaborone, Botswana

Full list of author information is available at the end of the article
}

C C The Author(s). 2021 Open Access This article is licensed under a Creative Commons Attribution 4.0 International License, which permits use, sharing, adaptation, distribution and reproduction in any medium or format, as long as you give appropriate credit to the original author(s) and the source, provide a link to the Creative Commons licence, and indicate if changes were made. The images or other third party material in this article are included in the article's Creative Commons licence, unless indicated otherwise in a credit line to the material. If material is not included in the article's Creative Commons licence and your intended use is not permitted by statutory regulation or exceeds the permitted use, you will need to obtain permission directly from the copyright holder. To view a copy of this licence, visit http://creativecommons.org/licenses/by/4.0/ The Creative Commons Public Domain Dedication waiver (http://creativecommons.org/publicdomain/zero/1.0/) applies to the data made available in this article, unless otherwise stated in a credit line to the data. 


\section{Introduction}

Globally, cervical cancer is the fourth most common cancer in women in terms of both incidence and mortality, with $85 \%$ of disease burden falling on women in low- and middle-income countries [1]. Chronic persistent human papillomavirus (HPV) infection is known to be the most critical risk factor for the development of cervical cancer [2], and co-infection with human immunodeficiency virus (HIV) increases the likelihood of cervical cancer development [3].

In Botswana, a middle-income country in sub-Saharan Africa (SSA), cervical cancer is the leading cancer type in females in terms of both incidence and mortality [1]. Additionally, HIV is hyperendemic in the nation with peak prevalence of $50.6 \%$ in females 35-39 years old [4]. Since initiating a publicly-funded antiretroviral therapy (ART) program in 2002, an aging population living with HIV infection has emerged in Botswana, and, subsequently, the incidence of cervical cancer has increased by $3.0 \%$ annually [5].

For individuals who have been diagnosed with locally advanced cervical cancer, the global standard-of-care includes concurrent radiotherapy and cisplatin-based chemotherapy [6]. The potential effects of HIV infection on cervical cancer survival and treatment toxicity, however, were previously poorly described. Thus, we have sought to elucidate these potential effects by prospectively comparing a cohort of WLWH receiving chemoradiation (CRT) to those without HIV infection receiving the same treatment in Botswana.

Our previous report comparing survival rates after two years of follow-up found that HIV status was not associated with 2-year overall survival (OS) in WLWH on ART who initiated curative CRT [7]. This letter serves to expand upon our previous results and compares survival in WLWH and without HIV infection after concluding 5 years of follow-up.

\section{Methods \& materials}

This observational cohort study prospectively enrolled women with locally advanced cervical cancer who were initiating curative chemoradiation at the only radiation facility in Gaborone, Botswana between July 2013 and January 2015. Treatment with curative intent was defined as a prescription of 45 to 50 Gray (Gy) of wholepelvis RT, weekly concurrent cisplatin $(35-40 \mathrm{mg} / \mathrm{m} 2)$ for 5 cycles, and high-dose-rate brachytherapy (7 Gy in 3-4 fractions or 6 Gy in 4-5 fractions). Five-year followup data collection concluded in February 2020. For complete method details see Grover et al. [7]

Upon initial enrollment, patient data including demographics and clinical characteristics were collected via patient interview and chart abstraction. Chemotherapy cycles were recorded weekly. Total radiation dose received at the conclusion of treatment was calculated via the radiobiological equivalent dose (EQD2) formula [8].

Follow up was conducted by phone every three months. If patients were not available, next of kin were contacted and medical records were reviewed for documentation indicating last appointment or death.

This study was reviewed and approved by an institutional review board in the USA and the Ministry of Health in Botswana.

\section{Results}

For complete demographics, clinical characteristics, and treatment parameters, please refer to Grover et al. [7] Briefly, a majority of patients were WLWH $(n=96,67 \%)$ with median CD4 count of 481 cells $/ \mu \mathrm{L}$ (interquartile range (IQR), 351-579 $\mu \mathrm{L}$ ) and median time on ART of 84 months (IQR, 24-120 months). The median age of WLWH was 43.4 years, significantly younger than those without HIV infection at 53.9 years $(p=0.004)$. Patients who presented with stage I, II, III or IV disease accounted for $14.9,60.6,24.5$, and $0 \%$ of the WLWH and $6.4,51.1,38.3$, and $4.3 \%$ of the cohort without HIV $(p=0.04)$. Baseline hemoglobin significantly differed between WLWH and without HIV infection $(p=0.04)$, with $10.6 \mathrm{~g} / \mathrm{dL}$ (95\% confidence interval (CI), 9.2-12.1) and $11.3 \mathrm{~g} / \mathrm{dL}$ (95\% CI, 10.5-13), respectively. Treatment received by patients did not differ by HIV status, with WLWH receiving a median dose of 79.8 Gy (IQR, 74$79.8 \mathrm{~Gy})$ and $58.3 \% \quad(n=56)$ receiving $\geq 4$ cycles of chemotherapy and patients without HIV infection receiving $79.8 \mathrm{~Gy}$ (IQR, 68.8-79.8 Gy) and 53.2\% receiving $\geq 4$ cycles. OS at 2 years was $65.5 \%$ (95\% confidence interval [CI] 56-73\%) overall, 65.0\% (95\% CI 54-74\%) for WLWH, and $66.0 \%$ (95\% CI 49-79\%) for patients without HIV infection.

Analysis at 5 years had a median follow-up time for all patients of 37.6 months (63.0 months for living patients). Five-year OS was 55.6\% (95\% CI, 46.6-63.7\%) for all patients, $56.8 \%(95 \%$ CI, 40.0-70.5\%) for patients without HIV infection, and 55.1\% (95\% CI, 44.2$64.7 \%)$ for WLWH $(p=0.732)$ (Fig. 1). On univariate analysis, baseline hemoglobin level $>10 \mathrm{~g} / \mathrm{dL}$ was associated with better OS, while poorer OS was associated with higher initial stage at diagnosis (stage III and IV) and receipt of $<2$ chemotherapy cycles (Table 1). After adjusting for HIV status, age, stage, number of chemotherapy cycles received, baseline hemoglobin, and total radiation dose (EQD2), multivariate analysis demonstrated that baseline hemoglobin $\geq 10 \mathrm{~g} / \mathrm{dL}$ remained associated with improved survival and advanced stage (stage III and IV) remained associated with poorer survival (Table 1). Notably, neither univariate nor multivariate analyses found that HIV status was associated with poorer survival in this cohort. 


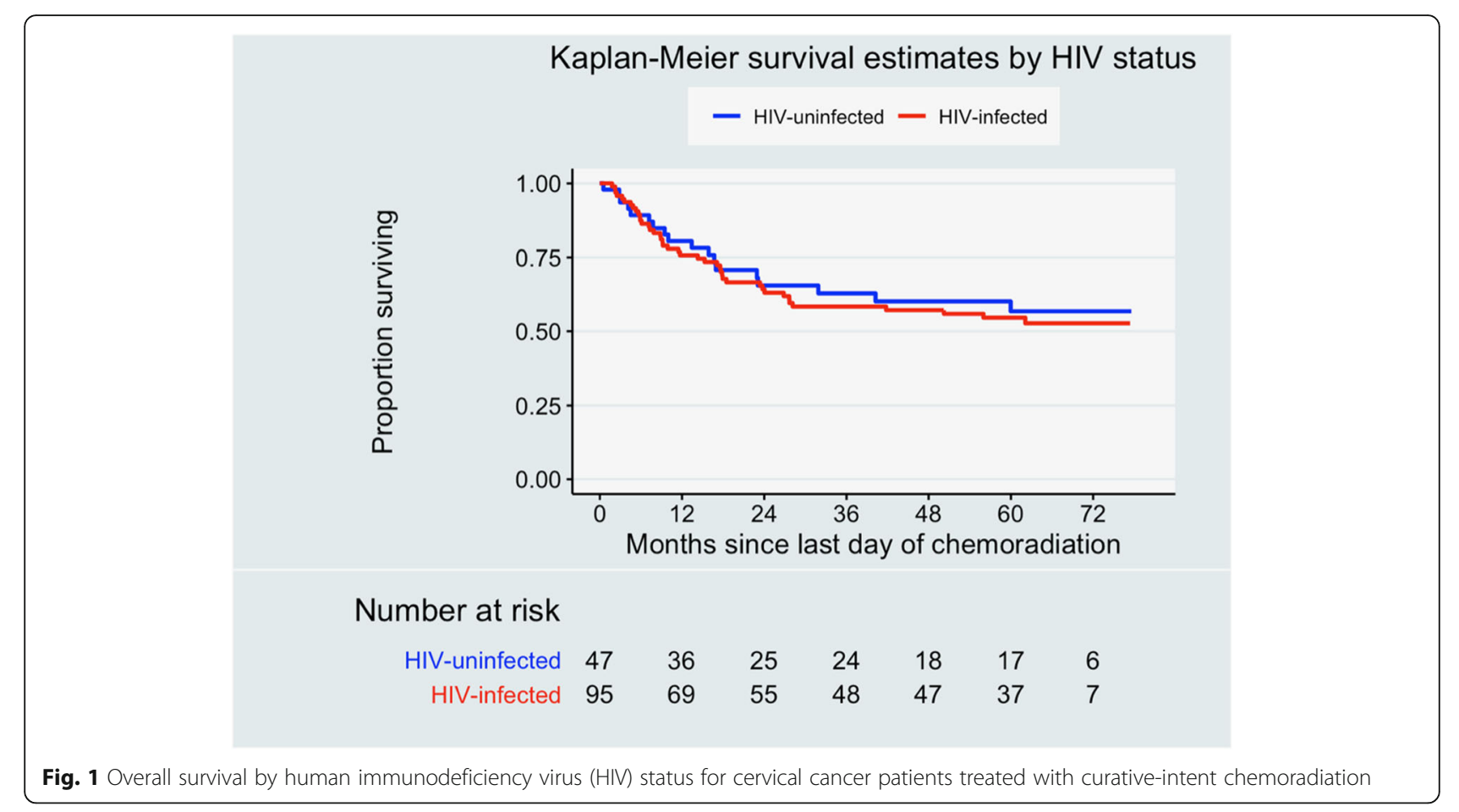

Table 1 Predictors of death at five years for cervical cancer patients in Botswana who initiated curative chemoradiation treatment

\begin{tabular}{|c|c|c|c|c|c|c|}
\hline \multirow[t]{2}{*}{ Variable } & \multicolumn{3}{|l|}{ Univariate } & \multicolumn{3}{|l|}{ Multivariate } \\
\hline & $\mathrm{HR}$ & \multicolumn{2}{|c|}{$95 \% \mathrm{Cl}$} & HR & \multicolumn{2}{|c|}{$95 \% \mathrm{Cl}$} \\
\hline Uninfected & Reference & & & & & \\
\hline Infected & 1.101311 & .6339304 & 1.913278 & 1.250879 & .657968 & 2.378075 \\
\hline \multicolumn{7}{|l|}{ Stage } \\
\hline$|A| B$ & Reference & & & & & \\
\hline$\|A\| B$ & 3.229473 & .991521 & 10.51868 & 2.72587 & .802824 & 9.255287 \\
\hline IIIA IIIB IV & 4.204608 & 1.255063 & 14.08593 & 3.747349 & 1.08663 & 12.9231 \\
\hline \multicolumn{7}{|l|}{ Age } \\
\hline$<40$ & Reference & & & & & \\
\hline $40-59$ & 1.225026 & .6760837 & 2.219677 & 1.617596 & .8523011 & 3.070061 \\
\hline$>60$ & 1.445736 & .6559022 & 3.186681 & 1.953187 & .8017136 & 4.758482 \\
\hline \multicolumn{7}{|l|}{ Baseline $\mathrm{Hb}$} \\
\hline$\leq 10$ & Reference & & & & & \\
\hline$>10$ & 0.4893405 & .292142 & .8196497 & 0.4624402 & .256955 & .8322505 \\
\hline \multicolumn{7}{|l|}{ Chemo cycles } \\
\hline 1 & 2.442394 & 1.191725 & 5.005592 & 1.992836 & .9455122 & 4.200256 \\
\hline 2 & 1.039553 & .4325541 & 2.498349 & 0.7922305 & .3125914 & 2.007826 \\
\hline 3 & 1.202074 & .6371535 & 2.26787 & 1.269207 & .659052 & 2.444246 \\
\hline$\geq 4$ & Reference & & & & & \\
\hline \multicolumn{7}{|l|}{ Final EQD2 } \\
\hline$<75$ & Reference & & & & & \\
\hline$\geq 75$ & 1.011468 & .9875201 & 1.035996 & 1.01332 & .9895877 & 1.037622 \\
\hline
\end{tabular}




\section{Discussion}

Understanding the impact of HIV infection on cervical cancer treatment outcomes is critical to providing optimal care to women around the globe. Our analysis of this prospective cohort with locally advanced cervical cancer in Botswana living with well-controlled HIV infection previously demonstrated that 2-year OS was not impacted by HIV status ${ }^{7}$. Improved 2-year survival was associated with baseline hemoglobin level $>10 \mathrm{~g} / \mathrm{dL}$, receipt of a total radiation dose $\geq 75 \mathrm{~Gy}$, and age $<40$ years. WLWH were not preferentially prescribed non-curative treatment compared to those without HIV in this cohort [9]. This follow-up analysis at 5 years continues to demonstrate that HIV status does not impact survival outcomes of women with cervical cancer treated in Botswana. While $34.5 \%$ of patients were deceased at two years, only an additional $9.9 \%$ were deceased at five years, as would be expected in cervical cancer where the majority of deaths occur in the first two years [10]. Similar to our previous findings, hemoglobin levels $>10 \mathrm{~g} / \mathrm{dL}$ remained an important predictor of survival at 5 years.

Our updated analysis provides an important addition to the available literature regarding long-term cervical cancer outcomes for WLWH with well-managed infection [11]. Since the publication of our 2-year data in January 2018, only one study has published data with extensive clinical follow-up. Simonds and colleagues [12] conducted a study in South Africa between 2007 and 2011 and concluded that HIV infection was associated with poorer 5-year survival. However, the proportion of WLWH infection in the cohort was small (14\%). Given that the period of data collection occurred earlier in the era of ART availability compared to our study, $40 \%$ of patients were not taking ART at the time of cancer diagnosis, and the median CD4 count was just over 350 cells/uL. These differences in patient populations are similar to those of other studies, including Coghill et al [13], Dryden-Peterson et al [14], and Ferreira et al [15] that have reported findings discordant with our own. Thus, the data presented here demonstrate the importance of medical management of HIV before cervical cancer is detected and treated as well as underscore the critical nature of public health efforts to increase HPV vaccination, broaden screening efforts, and provide sufficient ART to all WLWH. Furthermore, our 5-year results indicate that WLWH with well-managed infection have outcomes that do not differ from those without HIV infection and therefore should be prescribed curative standard-of-care treatment for locally advanced cervical cancer.

\section{Abbreviations}

HIV: human immunodeficiency virus; WLWH: women living with HIV;

ART: antiretroviral therapy; HPV: human papillomavirus; SSA: sub-Saharan Africa;
CRT: chemoradiation; OS: overall survival; Gy: Gray; EQD2: radiobiological equivalent dose; IQR: interquartile range; Cl: confidence interval

\section{Acknowledgements}

We acknowledge with thanks the contributions of Erle Robertson, Keba Ngoni, Lame Bakwenabatsile, Kesego Phologo and Tapologo Leselwa.

\section{Authors' contributions}

Study conception and design: LL, NZ, SG; Data acquisition: EM, MBN, SC DB, SG; Data analysis and interpretation: EM, JG, ST, SG, AC; Manuscript drafting: EM, AC; Critical revision: LL, NZ, DR, SG. All authors read and approved the final manuscript.

\section{Funding}

Center for AIDS Research (5-P30-Al-045008-17), Conquer Cancer Foundation Young Investigator Award, Sub-Saharan African Collaborative HIV and Cancer Consortia-U54 (1 U54 CA190158-01), Mentored Patient Oriented Career Research Development Award (1-K08CA230170-01A1), Department of Radiation Oncology, University of Pennsylvania.

\section{Availability of data and materials}

The datasets used and/or analysed during the current study are available from the corresponding author on reasonable request.

\section{Declarations}

Ethics approval and consent to participate

This study was reviewed and approved by an institutional review board in the USA and the Ministry of Health in Botswana.

Consent for publication

Not applicable.

\section{Competing interests}

The authors declare that they have no competing interests.

\section{Author details}

${ }^{1}$ Department of Radiation Oncology, Perelman School of Medicine, University of Pennsylvania, Philadelphia, USA. ²Department of Oncology, Gaborone Private Hospital, Gaborone, Botswana. ${ }^{3}$ Princess Marina Hospital, Gaborone, Botswana. ${ }^{4}$ Department of Family and Community Health, Penn State Health St. Joseph, Hershey, USA. ${ }^{5}$ Donald Bren School of Information \& Computer Sciences, University of California Irvine, Irvine, USA. ${ }^{6}$ Department of Radiation Oncology, University of Texas MD Anderson Cancer Center, Houston, USA. ${ }^{7}$ Botswana-University of Pennsylvania Partnership, Gaborone, Botswana. ${ }^{8}$ School of Medicine, University of Botswana, Gaborone, Botswana.

${ }^{9}$ Department of Obstetrics and Gynecology, University of Botswana, Gaborone, Botswana.

Received: 2 March 2021 Accepted: 16 June 2021

Published online: 03 August 2021

\section{References}

1. Bray F, Ferlay J, Soerjomataram I, Siegel RL, Torre LA, Jemal A. Global cancer statistics 2018: GLOBOCAN estimates of incidence and mortality worldwide for 36 cancers in 185 countries. CA Cancer J Clin. 2018;68(6):394-424. https://doi.org/10.3322/caac.21492.

2. Walboomers JM, Jacobs MV, Manos MM, Bosch FX, Kummer JA, Shah KV, et al. Human papillomavirus is a necessary cause of invasive cervical cancer worldwide. J Pathol. 1999;189(1):12-9. https://doi.org/10.1002/(SICI)10969896(199909)189:1<12::AID-PATH431>3.0.CO;2-F.

3. Del Mistro A, Bianchi LC. HPV-related neoplasias in HIV-infected individuals. Eur J Cancer. 2001;37(10):1227-35. https://doi.org/10.1016/S0959-8049(01)00107-1.

4. Botswana Ministry of Health. Botswana HIV/AIDS Impact Survey IV Results. Available at: http://www.statsbots.org.bw/sites/default/files/publications/ Botswana\%20AIDS\%20 Impact\%20Survey\%20Summary\%20\%20Apr202014. pdf. Accessed 16 April 2020.

5. Dryden-Peterson S, Medhin H, Kebabonye-Pusoentsi M, Seage GR III, Suneja $\mathrm{G}$, Kayembe MK, et al. Cancer incidence following expansion of HIV treatment in Botswana. PLoS One. 2015;10(8):e0135602. https://doi.org/10.13 71/journal.pone.0135602. 
6. Chuang LT, Temin S, Camacho R, Dueñas-Gonzalez A, Feldman S, Gultekin M, et al. Management and care of women with invasive cervical cancer: American Society of Clinical Oncology resource-stratified clinical practice guideline. J Glob Oncol. 2016;2(5):311-40. https://doi.org/10.1200/JGO.2016.003954.

7. Grover S, Bvochora-Nsingo M, Yeager A, Chiyapo S, Bhatia R, MacDuffie E, et al. Impact of human immunodeficiency virus infection on survival and acute toxicities from chemoradiation therapy for cervical cancer patients in a limited-resource setting. Int J Radiat Oncol Biol Phys. 2018;101(1):201-10,

8. American Brachytherapy Society. Brachytherapy guidelines and consensus statements. Reston: American Brachytherapy Society; 2016.

9. Grover S, MacDuffie EC, Wang Q, Bvochora-Nsingo M, Bhatia RK, Balang D, et al. HIV infection is not associated with the initiation of curative treatment in women with cervical cancer in Botswana. Cancer. 2019;125(10):1645-53. https://doi.org/10.1002/cncr.31972.

10. Howlader NN, Noone AM, Krapcho M, Miller D, Brest A, Yu M, Ruhl J, Tatalovich Z, Mariotto A, Lewis DR, Chen HS. SEER cancer statistics review, 1975-2017. National Cancer Institute; 2020.

11. Shah S, Xu M, Mehta P, Zetola NM, Grover S. Differences in Outcomes of Chemoradiation in Women With Invasive Cervical Cancer by Human Immunodeficiency Virus Status: A Systematic Review. Pract Radiat Oncol. 2021;11(1):53-65.

12. Simonds HM, Botha MH, Neugut Al, Van Der Merwe FH, Jacobson JS. Fiveyear overall survival following chemoradiation among HIV-positive and HIVnegative patients with locally advanced cervical carcinoma in a south African cohort. Gynecol Oncol. 2018;151(2):215-20. https://doi.org/10.1016/j. ygyno.2018.08.038

13. Coghill AE, Shiels MS, Suneja G, Engels EA. Elevated cancer-specific mortality among HIV-infected patients in the United States. J Clin Oncol. 2015;33(21): 2376-83. https://doi.org/10.1200/JCO.2014.59.5967.

14. Dryden-Peterson S, Bvochora-Nsingo M, Suneja G, Efstathiou JA, Grover S, Chiyapo S, et al. HIV infection and survival among women with cervical cancer. J Clin Oncol. 2016;34(31):3749-57. https://doi.org/10.1200/JCO.2016. 67.9613.

15. Ferreira MP, Coghill AE, Chaves CB, Bergmann A, Thuler LC, Soares EA, et al. Outcomes of cervical cancer among HIV-infected and uninfected women treated at the Brazilian National Institute of Cancer (2001-2013). AIDS (London, England). 2017;31(4):523.

\section{Publisher's Note}

Springer Nature remains neutral with regard to jurisdictional claims in published maps and institutional affiliations.

Ready to submit your research? Choose BMC and benefit from:

- fast, convenient online submission

- thorough peer review by experienced researchers in your field

- rapid publication on acceptance

- support for research data, including large and complex data types

- gold Open Access which fosters wider collaboration and increased citations

- maximum visibility for your research: over $100 \mathrm{M}$ website views per year

At $\mathrm{BMC}$, research is always in progress.

Learn more biomedcentral.com/submissions 